Psychopharmacologia (Berl.) 29, 307-315 (1973)

(C) by Springer-Verlag 1973

\title{
Effects of Stress and REM Sleep Deprivation on the Patterns of Avoidance Learning and Brain Acetylcholine in the Mouse*
}

\begin{abstract}
Teresa Sagales** and Edward F. Domino
Michigan Neuropsychopharmacology Research Program

Department of Pharmacology, University of Michigan, Ann Arbor, Michigan 48104

Received March 6, 1972; Final Version August 7, 1972

Abstract. Pure bred DBA/2J mice were subjected to varying degrees of stress and "water tank" REM sleep deprivation using one-animal cages, large platforms and/or poles. Subsequently, the animals were studied for acquisition, short-term and long-term retention using a conditioned avoidance procedure in a Warner type automated shuttle box. In addition, various groups of animals subjected to the same stressful procedures were sacrificed and brain acetylcholine ( $\mathrm{ACh}$ ) was measured by the frog rectus abdominus muscle bioassay. It was found that stress and REM sleep deprivation had no significant effect on acquisition and short-term retention but did impair long term retention of conditioned behavior. Moderate environmental stress also produced significant behavioral changes. Total brain $\mathrm{ACh}$, under these environmental conditions, showed no significant changes from normal.
\end{abstract}

Key words: Acetylcholine - REM Sleep Deprivation - Avoidance Learning.

A relationship between sleep and memory was experimentally suggested as early as 1924 by Jenkins and Dallenbach. According to these authors, sleep after learning would facilitate retention through avoiding interferences from new experiences. Although this seems to be partially true, a more active role of sleep has been suggested in recent times. The abundance of REM sleep in the early ages of life, when learning is maximal, may indicate a link between REM sleep and information processing. Several experiments, designed to test this hypothesis, have shown that REM sleep deprivation may alter the acquisition and retention of learned behavior (Fishbein, 1969 a ; Stern, 1969, 1970; Albert et al., 1970). However, the procedures currently used for achieving REM sleep deprivation always involve a component of stress and environmental restriction. The role of the latter has not always been adequately assessed.

The present study was designed to investigate the effects of two stressful environments, one of them involving REM sleep deprivation, on

\footnotetext{
* Supported in part by grant MH-11846, USPHS.

** Present address: Universidad Autónoma de Barcelona, Facultad de Medicina, Departamento de Ciencias Fisiológicas, Barcelona, Spain. 
acquisition and retention of avoidance conditioning in the mouse. In addition, some data on the effects on total brain acetylcholine ( $\mathrm{ACh})$ are also included.

\section{Methods}

A total of $123 \mathrm{DBA} / 2 \mathrm{~J}$ male mice was used. Their average weight was $25 \mathrm{~g}$ and the age range was $2^{1} / 2$ to 3 months.

Environments. Four different environments, involving different degrees of stress, were used. These included:

a) Community cages: These were the common mouse cages, housing 12 mice together, currently used in our animal facilities. These measure $20 \times 25 \times 40 \mathrm{~cm}$.

b) One-animal cages: Each cage, cylindrical in shape, $25 \mathrm{~cm}$ in diameter and $30 \mathrm{~cm}$ high housed one animal.

c) Platforms: A round wood platform, $25 \mathrm{~cm}$ in diameter, kept $3 \mathrm{~cm}$ above water in a $40 \times 40 \mathrm{~cm}$ pool. A small ladder was attached to the platform in order to facilitate emergence in case the animal fell. Water in a little vase and food placed on a grill $4 \mathrm{~cm}$ above the platform were available at all times. This was the low level of stress environment.

d) Poles: A pole, $3 \mathrm{~cm}$ in diameter with a parabolical end, providing a supporting area of $1 \mathrm{~cm}^{2}$, was placed $3 \mathrm{~cm}$ above water in a $40 \times 40$ pool. Water could be drunk from the pool and food, placed on a grill $3 \mathrm{~cm}$ above the pool, was available at all times. This was the high level of stress environment, involving REM sleep deprivation.

The same room environment (size of the room, temperature, humidity and light) was maintained in all cases. A 25 watt, $110 \mathrm{v}$, a.c. lamp, in a $6 \times 4 \mathrm{~m}$ room was used as a weak light source at night from 7:00 p.m. to 7:00 a.m. The temperature of the water in the pools was also controlled at approximately $30^{\circ} \mathrm{C}$.

Sleep Studies. Six chronically implanted steel electrodes were used for $24 \mathrm{~h}$ recording of sleep in 5 mice. The electrodes were placed on the cerebral cortex and the nasion (indifferent electrode) for EEG recording, in the vieinity of the eyes for EOG recording, and in the neck muscles for EMG recording.

Acetylcholine Brain Levels. Animals were sacrificed by guillotine, the brain removed and homogenized in acid-alcohol for extraction of total $\mathrm{ACh}$ via the method. of Stone (1955) and bioassayed on the isolated rectus abdominus muscle preparation of Rana pipiens as modified by Dren and Domino (1968). ACh standards were prepared in alkali-inactivated extracts to control the presence of sensitizing factors in the brain tissue.

Avoidance Conditioning. Avoidance conditioning was studied using an automated two way Warner "shuttle box" similar to that used by Bovet et al. (1966). The apparatus consisted of a rectangular Plexiglas box $(25 \times 10 \mathrm{~cm})$ divided into 2 equal compartments connected by a small opening. The floor was made of stainless steel rods. The conditioned stimulus (CS) consisted of a 10 watt light and a high pitch buzzer noise. It preceded the unconditioned stimulus (US) by 5 sec. The unconditioned stimulus was an electrical shock of $1.5 \mathrm{~mA}$, lasting for 5 sec and delivered through the floor rods. The mice could avoid the shock by running into the opposite compartment of the box within $5 \mathrm{sec}$ after the onset of the conditioned stimulus. Each trial session consisted of 100 consecutive trials. An adaptation period of 5 min in the box preceded each session.

Procedures. Two different experimental procedures were used.

Experiment 1 . Forty-five mice were kept continuously either in one-animal cages or on platforms for 6 days. After this habituation period they were randomly 
assigned to 3 different experimental environments; 15 animals which were in oneanimal cages during the habituation period remained there. Another 15 mice kept on platforms were transferred to the poles and the last 15 mice remained on the platforms. After $24 \mathrm{~h}$ in the above environments, the mice received their first session of training. Immediately after the training, all animals were transferred to common eages and kept there for 8 days. After this period of rest, a second session of training was given.

Experiment II. The design was similar to Experiment I, except: a) Each group was composed of 16 animals, b) following the first session of training, a second $24-h$ period in the experimental environments (the same as in the $24 \mathrm{~h}$ prior to training) was introduced, c) another session of training followed this second 24 -h period.

A schematic representation of the experimental procedure is shown in Fig.1.

\section{Results}

Experiment $I$. The acquisition and retention data concerning avoidance training in this experiment are shown in Table 1. Acquisition performance was lower in animals kept on platforms for $24 \mathrm{~h}$ prior to the first training than in those kept in one-animal cages or on poles. The differences are statistically significant at the level of $P<0.02$ and $P<0.02$, respectively, using a group comparison student's " $t$ " test. No statistically significant differences were observed between mice kept in the single animal cages with respect to those on poles.

When tested for retention, after an 8 day rest period in common cages, the performance of mice placed in one-animal cages and on platforms

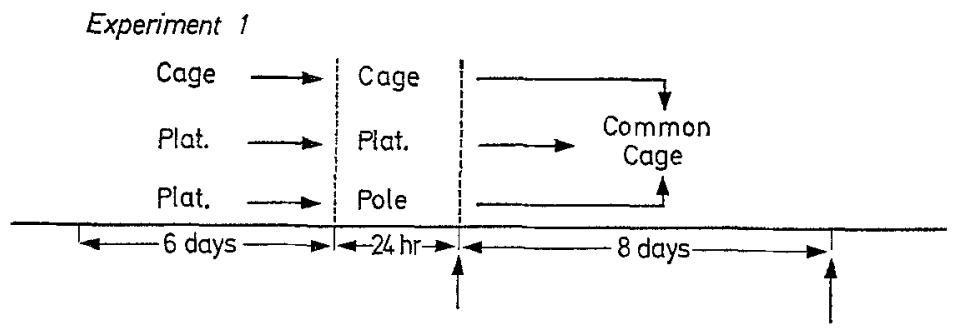

Experiment 2

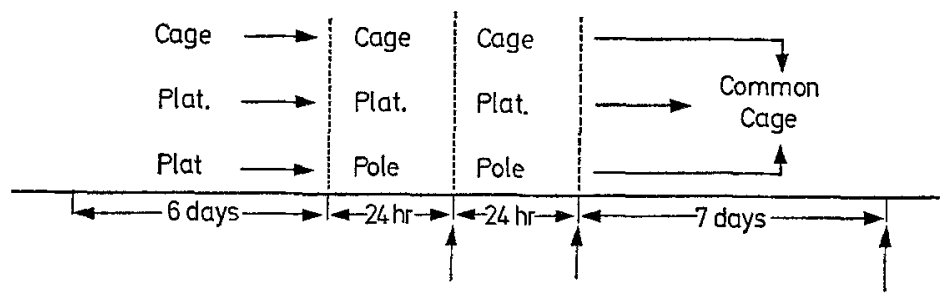

Fig. 1. Schematic representation of the experimental design. Arrows at the baseline indicate time of training, acquisition and short-term retention in experiment I and acquisition, short-term and long-term retention in experiment II 
Table 1. Percent avoidance behavior for acquisition and retention of mice placed in various environments

\begin{tabular}{lcl}
\hline Environment & $\begin{array}{c}\text { 1st training } \\
\text { (acquisition) }\end{array}$ & $\begin{array}{l}\text { 2nd training } \\
\text { (8-day-retention) }\end{array}$ \\
\hline Single Cage & $21.5 \pm 3.9$ & $83.2 \pm 3.1$ \\
Platform & $9.8 \pm 3.0^{*}$ & $80.6 \pm 2.8$ \\
Poles & $17.7 \pm 1.3$ & $69.7 \pm 3.4^{* *}$ \\
\hline
\end{tabular}

Mean \pm SE of groups of mice given 100 trials each are listed. The animals were placed in different environments $24 \mathrm{~h}$ prior to the training trials.

* Platform vs single cage, $P<0.02$; Platform vs pole, $P<0.02$.

** Pole vs single cage, $P<0.005$; Pole vs platform, $P<0.02$.

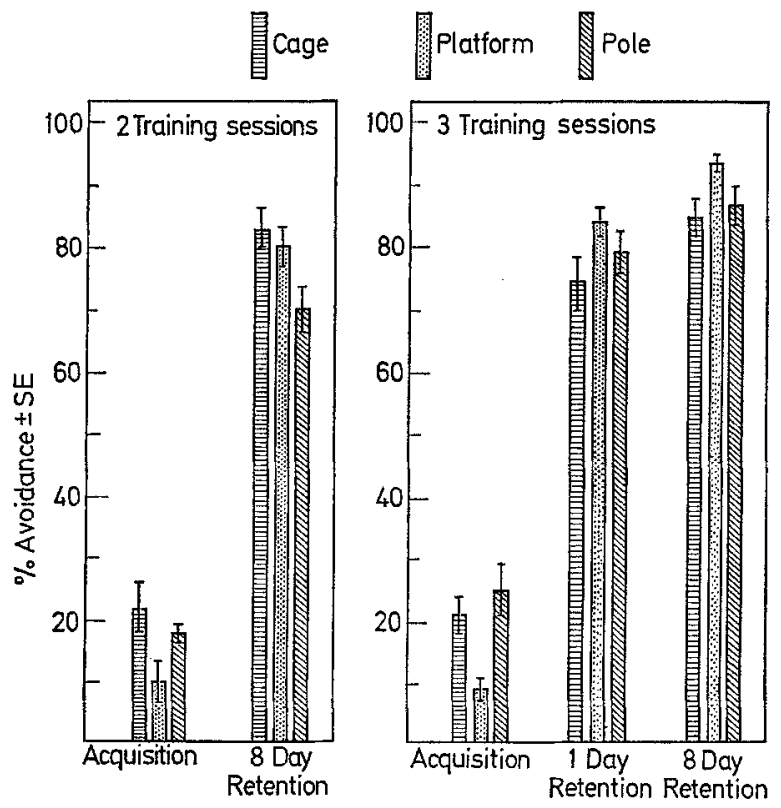

Fig. 2. Schematic representation of the patterns of avoidance conditioning in the two and three training sessions of experiments I and II. The lined areas represent total percent of avoidances. The bar graphs to the left represent the two training sessions of experiment I and the bar graphs to the right the three training sessions of experiment II. All data represent groups of mice given 100 trials per session of training

was equal. The animals kept on poles, however, markedly differed from the others, showing lower retention values, the difference being again statistically significant at the levels of $P<0.005$ and $P<0.02$ (for the one-animal cages and the platforms, respectively). 
Table 2. Percent avoidance behavior for acquisition and retention of mice placed in various environments

\begin{tabular}{lcll}
\hline Environment & $\begin{array}{l}\text { 1st training } \\
\text { (acquisition) }\end{array}$ & $\begin{array}{l}\text { 2nd training } \\
\text { (1-day-retention) }\end{array}$ & $\begin{array}{l}\text { 3rd training } \\
\text { (8-day-retention) }\end{array}$ \\
\hline Single Cage & $20.8 \pm 3.3$ & $74.1 \pm 4.0$ & $86.4 \pm 3.1$ \\
Platform & $8.8 \pm 1.6^{*}$ & $83.9 \pm 2.3^{* *}$ & $93.6 \pm 0.9$ \\
Poles & $24.1 \pm 4.4$ & $79.0 \pm 3.2$ & $85.7 \pm 2.9$ \\
\hline
\end{tabular}

Mean $\pm \mathrm{SE}$ of groups of mice given 100 trials each are listed. The animals were placed in different environments $24 \mathrm{~h}$ prior and $24 \mathrm{~h}$ after the first training trials.

* Platform vs single cage, $P<0.005$; Platform vs pole, $P<0.001$.

** Platform vs single cage, $P<0.05$.

Experiment II. Data concerning acquisition and short-and long-term retention of avoidance conditioning in Experiment II are given in Table 2. Acquisition performance was similar to that in Experiment I. See Fig. 2. The mean number of avoidance in the first session of training was lower in mice kept on platforms than in those placed in one-animal cages or on poles $(P<0.005$ and $P<0.001$, respectively). No difference was observed between the mice in one-animal cages and those on poles.

As far as the second training session was concerned, the mice kept on platforms before and after the acquisition training showed a higher degree of retention than those kept in one-animal cages or on poles. This difference, however, was only significant with respect to mice in oneanimal cages $(P<0.05)$.

When tested for long-term retention, after an 8 day rest period, the score was again higher for the mice kept on platforms during the active phase of the experiment. The difference was statistically significant with respect to the performance of the mice in one-animal cages or on poles $(P<0.05$ and $P<0.02$, respectively).

Sleep. As measured by polygraphic techniques, it appeared that almost complete REM sleep suppression was achieved in animals kept on poles. REM sleep was present and similar in mice placed in the other experimental conditions.

Brain Acetylcholine Levels. The effects of stress and REM sleep deprivation on steady state levels of brain ACh were remarkably negative under the conditions of our experiments. Brain ACh was essentially normal under all conditions as listed in Table 3.

\section{Discussion}

Our results indicate that the acquisition of avoidance conditioning can be modified by changes in environment prior to the training. Since 
Table 3. Lack of effects of "water tank" REM sleep deprivation on total mouse brain acetylcholine levels

\begin{tabular}{lrll}
\hline Environment & $N$ & Mean $\pm \mathrm{SE}$ ACh & $P^{*}$ value \\
\hline Single Cage Control & 6 & $18.4 \pm 1.1$ & - \\
Group Cage Control & 6 & $18.5 \pm 1.4$ & - \\
Platform (6 days) & 7 & $20.6 \pm 1.4$ & Not significant \\
Pole $(24 \mathrm{~h})$ & 10 & $17.6 \pm 1.2$ & Not significant \\
Pole $(48 \mathrm{~h})$ & 4 & $20.0 \pm 0.6$ & Not significant \\
Pole $(96 \mathrm{~h})$ & 5 & $18.2 \pm 0.9$ & Not significant \\
\hline
\end{tabular}

* Group comparison student's " $t$ " test compared to pooled controls.

mice kept on platforms performed worse than the controls placed in a practically normal environment (one-animal cages), it can be assumed that a slight degree of stress prior to the training impairs the acquisition of avoidance conditioning. However, when the stress is greater and involves REM sleep suppression, as in animals kept on poles, this impairment is not observed and neither is a facilitation, since these mice performed as well as those in one-animal cages. This was apparent in both Experiments I and II, as would be expected, since the experimental conditions were, so far, the same.

As far as long-term retention of acquired avoidance conditioning is concerned, the effect of slight stress prior to the acquisition training is no longer apparent. Mice kept on platforms performed as well as those in one-animal cages, but a disturbing effect of REM sleep deprivation (or a high degree of stress) prior to the acquisition training is manifest. Mice placed on poles for $24 \mathrm{~h}$ prior to the first training showed a poorer degree of long-term retention than those in one-animal cages or on platforms.

In one of our series of experiments, the effects of continued environment change after the first session was also studied. Contrary to what appeared in the acquisition studies, the slight degree of stress induced by keeping the mice on a platform had a facilitating effect upon short-term retention. This facilitation was less apparent than the impairment observed in the acquisition studies but it was still significant as far as one-animal per cage controls were concerned.

'The long-term retention of avoidance conditioning in animals subject to varying degrees of stress $24 \mathrm{~h}$ prior and $24 \mathrm{~h}$ after the acquisition training was also measured. Here, as in short-term retention studies, a facilitating effect of a slight degree of stress was apparent. REM sleep suppression in these studies, on the other hand, had no effect upon longterm retention. 
Published data concerning the role of REM sleep in learning are scarce and inconclusive. While some authors suggest that REM sleep deprivation prior to training impairs the acquisition of the trained task (Stern, 1969), others have argued that acquisition is not affected under these conditions, although long-term retention is impaired (Fishbein, $1969 \mathrm{~b}$ ). REM sleep deprivation following the acquisition training impairs short-term but not long-term retention (Fishbein, 1969a). Our results are in agreement with those of Fishbein (1969b) showing that REM sleep deprivation prior to avoidance conditioning does not affect acquisition but impairs long-term retention of the trained behavior.

Studies concerning the effects of REM sleep deprivation preceding and following avoidance conditioning are even rarer. Brill and Goodman (1969) have found that this procedure does not affect short-term retention in the cat. Our results in mice further substantiate their findings.

In all the above mentioned studies, including our own, REM sleep deprivation has been accomplished through procedures involving a marked degree of environmental stress. Joy and Prinz (1969) have shown that environmental changes markedly influence the acquisition and retention patterns of conditioned avoidance response in animals. Our data also show that a varying degree of stress may influence, even in opposite ways, the patterns of avoidance conditioning. The particular role of stress versus selective REM sleep deprivation is still to be determined. Perhaps studies on higher animals, using more sophisticated techniques of REM sleep deprivation, may clarify this point.

Our results show increased retention of learned avoidance in mice subject to moderate stress prior to and after the acquisition training. Obviously, the degree of stress is a critical variable which must be studied further. Its effects on total brain ACh appear negligible if steady state conditions are measured.

These negative data with whole mouse brain are to be contrasted with the findings of Bowers et al. (1966) and Tsuchiya et al. (1969) that REM sleep deprivation for $96 \mathrm{~h}$ reduces the ACh content of rat telencephalon while $24 \mathrm{~h}$ total sleep deprivation increases rat telencephalon content of ACh (Tsuchiya et al., 1969). No significant changes in ACh with either type of sleep deprivation were observed in the diencephalon and brainstem. Either this is the result of regional brain or species differences. Further research on the changes in regional brain $\mathrm{ACh}$ is clearly indicated.

It is of interest to compare the effects of REM deprivation on the brain levels of other biogenic amines. Generally, REM sleep deprivation for 3-4 days does not change endogenous brain norepinephrine or 5-hydroxytryptamine levels in the rat (Hartmann and Freedman, 1966; Pujol et al., 1968). Bliss (1965) also showed that 10 days of REM sleep 
deprivation did not change whole brain norepinephrine (NE) or 5-hydroxytryptamine (5-HT) in non-fatigued rats. Only Tsuchiya et al. (1969) reported that REM sleep deprivation reduced brain NE but did not distinguish this effect from stress.

Recently Stern et al. (1971) studied regional brain NE and 5-HT in REM deprived (3, 5, 6 and 8 days) and stress induced (5 days) rats and showed no significant differences. After pargyline, both groups showed equally elevated NE and 5-HT levels, suggesting enhanced amine synthesis.

The conventional "water tank" deprivation technique, in which animals are continually confined to a small platform surrounded by water, causes considerable stress, as evident by a marked body weight loss and adrenal gland hypertrophy (Stern, 1969; Mark et al., 1969).

In the present study marked body weight loss was also observed. Although we have not measured adrenal hypertrophy or corticosteroid levels, it is reasonable to assume that the environmental conditions were stressful. As mentioned earlier, further research on the role of stress per $s e$, vs REM sleep deprivation is clearly indicated.

\section{References}

Albert, I., Cicala, G. A., Siegel, J.: The behavioral effects of REM sleep deprivation in rats. Psychophysiol. 6, 550-560 (1970).

Bliss, E. L. : Sleep in schizophrenia and depression-Studies of sleep loss in man and animals. Ass. Res. nerv. Dis. Proc. 45, 195-210 (1967).

Bovet, D., Bovet-Nitti, F., Oliviero, A. : Effects of nicotine on avoidance conditioning of inbred strains of mice. Psychopharmacologia (Berl.) 10, 1-5 (1966).

Bowers, M. B., Hartmann, E. L., Freedman, D. X.: Sleep deprivation and brain acetylcholine. Science 153, 1416-1417 (1966).

Brill, R. W., Jr., Goodman, I. J.: Effects of REM sleep deprivation on memory in cats. Psychophysiol. 6, 226 (1969).

Dren, A. T., Domino, E. F.: Effects of hemicholinium (HC-3) on EEG activation and brain acetylcholine in the dog. J. Pharmacol. exp. Ther. 161, 141-154 (1968).

Fishbein, W.: The effects of paradoxical sleep deprivation during the retention interval on long-term memory. Psychophysiol. 6, 225 (1969a).

Fishbein, W.: The effects of paradoxical sleep deprivation prior to initial learning on long-term memory. Psychophysiol. 6, 225 (1969b).

Hartmann, E., Freedman, D. X.: The effect of "dream-deprivation" on brain serotonin and norepinephrine levels in the rat. Paper presented at the Meeting of the Association for the Psychophysiological Study of Sleep, Gainesville, Florida (1966).

Jenkins, J. G., Dallenbach, K. M.: Oblivescence during sleep and waking. Amer. J. Psychol. 35, 605-616 (1924).

Joy, R. M., Prinz, P. N.: The effect of sleep altering environments upon the acquisition and retention of a conditioned avoidance response in the rat. Physiol. Behav. 4, 809-814 (1969). 
Mark, J., Heinger, L., Mandel, P., Godin, Y.: Norepinephrine turnover in brain and stress reactions in rats during paradoxical sleep deprivation. Life Sci. 8, 1085 to $1093(1969)$.

Pujol, J. F., Mouret, J., Jouvet, M., Glowinski, J.: Increased turnover of cerebral norepinephrine during rebound of paradoxical sleep in the cat. Science 159, $112-114$ (1968).

Stern, W. C.: Effects of REM sleep deprivation upon the acquisition of learned behavior in the rat. Psychophysiol. 6, 224 (1969).

Stern, W. C.: Behavioral and biochemical aspects of rapid eye movement sleep deprivation in the rat. Diss. Abst. 31, 1574.B (1970).

Stern, W. C., Miller, F. P., Cox, R. H., Maickel, R. P.: Brain norepinephrine and serotonin levels following REM sleep deprivation in the rat. Psychopharmacologia (Berl.) 22, 50-55 (1971).

Stone, W. E. : Acetylcholine in the brain. I. "Free," "bound" and total acetylcholine. Arch. Biochem. Biophys. 59, 181-192 (1955).

Tsuchiya, K., Toru, M., Kobashi, T.: Sleep deprivation. Changes of monoamines and acetylcholine in rat brain. Life Sci. 8, 867-873 (1969).

E. F. Domino, M.D.

Department of Pharmacology

University of Michigan

Ann Arbor, Michigan 48104, U.S.A. 